\title{
Aportaciones al taller de Pedro Duque Cornejo en Granada
}

\author{
Manuel García LuQue \\ Universidad de Granada \\ Departamento de Historia del Arte \\ mgarcialuque@ugr.es
}

\section{RESUMEN}

Pedro Duque Cornejo, una de las figuras descollantes del barroco andaluz del XVIII, desarrolló su actividad fundamentalmente en Granada, Sevilla y Córdoba. Del olvido historiográfico del primero de estos escenarios trata el presente trabajo. Se traza un recorrido por sus viajes realizados entre 1713 y 1716 y se plantean nuevas hipótesis sobre su traslado a Granada en este último año. A partir de documentación inédita se reconstruye paso a paso la presencia de su taller en la ciudad, donde asumió importantes encargos hasta 1719.

Palabras clave: Duque Cornejo; Pedro; Escultura barroca; Retablo; Granada; Sevilla.

\section{Contributions to the Pedro Duque Cornejo's workshop in Granada}

\begin{abstract}
Pedro Duque Cornejo, one of the most prominent artists of the Andalusian baroque during $18^{\text {th }}$ century, developed his work mainly in Granada, Seville and Cordoba. This essay deals with the first of these places, less studied in the historiography. We draw a route by the travels he carried out between 1713 and 1716 and offer new hypothesis about his transfer to Granada in that last year. We also reconstruct step by step his workshop in the city, where he assumed important jobs until 1719, by means of new discovered information.
\end{abstract}

Key words: Duque Cornejo; Pedro; Baroque sculpture; Retablo; Granada; Sevilla. 
El sevillano Pedro Duque Cornejo y Roldán (1678-1757) fue uno de los artistas más destacados del XVIII español. Retablista, escultor, pintor y grabador, desarrolló su actividad en tres centros andaluces -Granada, Sevilla y Córdoba- en los que pudo colaborar estrechamente con arquitectos tan destacados como Jerónimo Balbás, Francisco Hurtado Izquierdo o Leonardo de Figueroa. A esta figura clave del barroco andaluz se han dedicado numerosos artículos, dos monografías y una tesis doctoral. Sin embargo, a pesar de estas investigaciones, sus años de formación sevillanos y, sobre todo, su etapa granadina, permanecen aún oscuros. El presente trabajo pretende arrojar luz precisamente sobre la actividad de Duque Cornejo y su taller en Granada ${ }^{1}$.

\section{ESTADO DE LA CUESTIÓN}

Antes de nada conviene hacer un breve repaso historiográfico, de interés para constatar las oscilantes cronologías que se propusieron para el periodo granadino de Duque Cornejo. Ceán Bermúdez retrasaba su paso por la ciudad a las tardías décadas de 1730 y $1740^{2}$, y un siglo más tarde, Manuel Gómez-Moreno González lo situaba en 1718, acabando el Apostolado de la iglesia de las Angustias ${ }^{3}$. El dato fue advertido por María Elena Gómez-Moreno en la segunda edición de su Breve Historia de la Escultura española (1951), en la que dedicó un espacio considerable a Pedro Duque Cornejo. Siguiendo lo aportado por su abuelo, en principio fijó la etapa de Granada entre 1716 y $1719^{4}$, aunque años más tarde la extendió notablemente de 1702 a 1725, basándose en sus colaboraciones con Hurtado Izquierdo ${ }^{5}$ : en el primer año, supuestamente ambos habrían colaborado en el retablo cordobés de la Magdalena ${ }^{6}$,

\footnotetext{
${ }^{1}$ A esta etapa dedicamos nuestro Trabajo de Investigación Tutelada Pedro Duque Cornejo en Granada (inédito), que fue dirigido por el Dr. Lázaro Gila Medina en 2010, a quien quiero hacer constar mi agradecimiento, así como a D. Antonio Muñoz Osorio, Delegado Diocesano para el Patrimonio Cultural de la Diócesis de Granada, por las facilidades dadas para llevar a cabo esta investigación. El artículo aquí publicado fue presentado como comunicación el 5 de mayo de 2011 en el III Encuentro Complutense de Jóvenes Investigadores de Historia del Arte. En el transcurso de su publicación ha visto la luz otro trabajo de la Dra. Gómez Román sobre la proyección del taller de Duque Cornejo en Granada, al que remitimos para mayor abundamiento: GÓMEZ ROMÁN, Ana María, "Contribución al estudio de la escultura andaluza del siglo XVIII: Pedro Duque Cornejo y su estela en Granada", en SERRANO ESTRELLA, Felipe (coord.), Docta Minerva: Homenaje a la profesora Luz de Ulierte Vázquez, Jaén, Universidad, 2011, pp. 83-94.

2 CEÁN BERMúdEZ, Juan Agustín, Diccionario Histórico de los Más Ilustres Profesores de las Bellas Artes en España, t. II, Madrid, Imp. de la Viuda de Ibarra, 1800, p. 23.

3 Se trata de una descripción de la iglesia de las Angustias redactada en 1918 y publicada en HITOS, Francisco A., Páginas Históricas de Nuestra Señora de las Angustias, $2^{\mathrm{a}}$ ed., Burgos, Aldecoa, 1929. También se puede encontrar en Obra dispersa e inédita. Manuel Gómez-Moreno González [compilación y estudio preliminar de Javier Moya Corrales], Granada, Instituto Gómez Moreno, 2004, pp. 466-469.

4 GÓMEZ-MORENO Y RODRIIGUEZ-BOLÍVAR, María Elena, Breve historia de la escultura española, $2^{\mathrm{a}}$ ed. refundida y ampliada, Madrid, Dossat, 1951 [ed. facsímil Jaén, Universidad de Jaén, 2001], p. 155.

5 GÓMEZ-MORENO Y RODRÍGUEZ-BOLÍVAR, María Elena, Escultura del siglo XVII [col. Ars Hispaniae, vol. XVI], Madrid, Plus Ultra, 1958, pp. 141-148.

6 Se creía que el retablo había sido ejecutado en 1702 por Teodosio Sánchez de Rueda, bajo diseño de Hurtado. Sin embargo, este retablo nunca llegó a materializarse. Como documentó M. ángeles Raya, el retablo actual lo realizó Alonso Gómez de Sandoval en 1771. Rafael Ramírez de Arellano lo atribuyó a Duque Cornejo y Santiago Alcolea creyó suyas las esculturas. Éstas deben ser contemporáneas a la ejecución del
} 
y en el último acabaría su contacto, con la muerte del arquitecto y el contrato de las esculturas de la cartuja de El Paular. La autora consagraba, además, una periodización canónica para la obra de Cornejo dividida en tres etapas: granadina (1702-1725), sevillana (1725-1747) y cordobesa (1747-1757); que fue la seguida, entre otros, por Hernández Díaz en su monografía sobre el $\operatorname{artista}^{7}$. Sin embargo, frente a esta postura, Ryan Howard, en su tesis doctoral ${ }^{8}$, y René Taylor, en la otra monografía sobre el artista $^{9}$, retomaron con acierto la cronología sugerida años atrás por Gallego y Burín para Granada: de 1714 a $1719^{10}$.

Al margen de estas fechas cambiantes, las propuestas más firmes sobre su marcha fueron lanzadas por Taylor, para quien Duque Cornejo y Hurtado Izquierdo se habrían conocido hacia 1710, en algún viaje del arquitecto a Sevilla ${ }^{11}$. Posteriormente Hurtado habría solicitado sus servicios, quizás para unos trabajos en la catedral Córdoba, de la que era maestro mayor y donde estaba levantado la capilla del cardenal Salazar. Para su cripta destinó ocho esculturas, cuatro retablos y unas yeserías, que le fueron pagadas a Teodosio Sánchez de Rueda en febrero de $1713^{12}$. Teniendo en cuenta que no se conocen otras esculturas de este ensamblador, cabe la posibilidad de que las hubiera subcontratado con un escultor de oficio, como era frecuente. Ciertamente, aunque las piezas no son de gran calidad, preludian el estilo de Duque, de manera que cabría rastrear la gubia del sevillano en ellas.

De todos modos, la hipótesis más solida sostenida por Taylor está relacionada con los púlpitos de la catedral de Granada (fig. 1). Éstos habían sido contratados en abril de 1713 por Hurtado Izquierdo -también maestro mayor de la catedral granadinapara ejecutarlos en mármoles polícromos, siguiendo un diseño florentino traído de Génova. Aunque el nombre de Duque Cornejo no aparece en ningún momento en la documentación, Taylor le atribuyó el apartado escultórico ${ }^{13}$.

retablo, muerto ya el maestro, aunque siguiendo sus modelos, como sugirió Aroca Lara. Vid. RAYA RAYA, María Ángeles, El retablo en Córdoba durante los siglos XVII y XVIII, Córdoba, Monte de Piedad y Caja de Ahorros de Córdoba, 1980, p. 129; AROCA LARA, Angel, "La obra de Pedro Duque Cornejo en Córdoba: su labor escultórica en los retablos de la Magdalena y la Compañía", en PELÁEZ DEL ROSAL, Manuel (dir.), Conferencias de los Cursos de Verano de la Universidad de Córdoba sobre "El barroco en Andalucía», vol. III, Córdoba, Monte de Piedad y Caja de Ahorros de Córdoba, 1986, pp. 11-24.

7 HERNÁNDEZ DÍAZ, José, Pedro Duque Cornejo [col. Arte Hispalense], Sevilla, Diputación Provincial, 1978.

8 HOWARD, Ryan Abney, Pedro Duque Cornejo (1678-1757), Michigan, University Microfilms International, 1991 [tesis doctoral, 1975], pp. 53-66.

9 TAYLOR, René, El entallador e imaginero sevillano Pedro Duque Cornejo (1678-1757), Madrid, Instituto de España, 1983, p. 35.

10 GALLEGO Y BURÍN, Antonio, El barroco granadino, Granada, Universidad, 1956 [reed. Granada, Comares, 1987], p. 102, n. 124.

11 TAYLOR, René, "Los púlpitos de la catedral de Granada y sus autores", en Boletín de Bellas Artes, no 6, 1978, p. 190.

12 TAYLOR, René, Arquitectura andaluza: los hermanos Sánchez de Rueda, Salamanca, Universidad, 1978, p. 64, n. 59.

13 TAYLOR, René (1978a), op. cit, p. 190. 


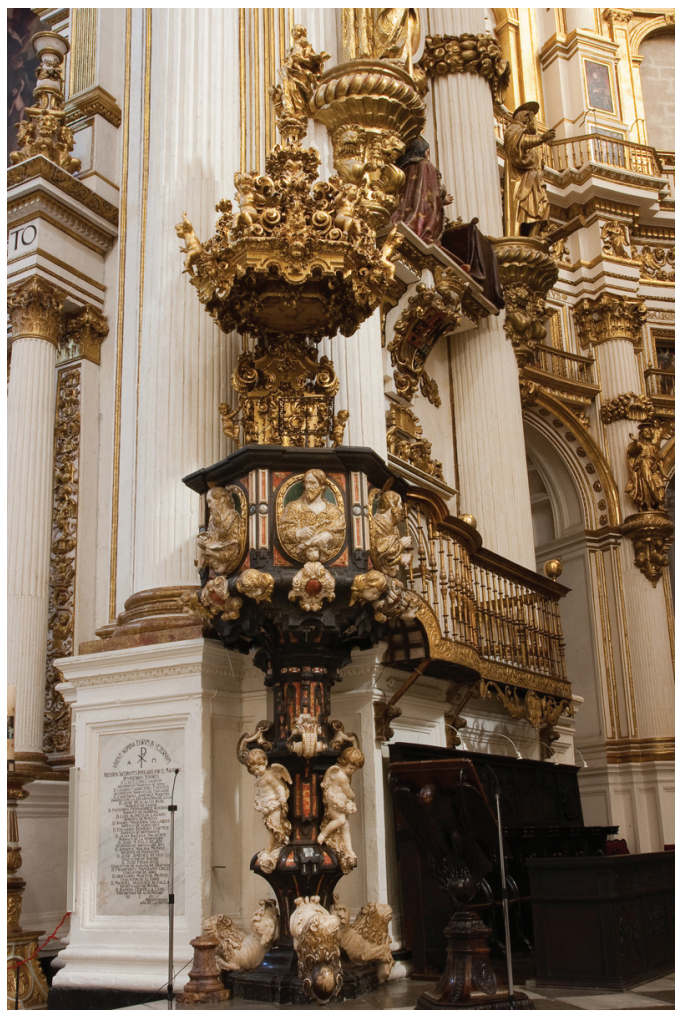

Fig. 1. Francisco Hurtado Izquierdo y Pedro Duque Cornejo, Púlpito (lado del Evangelio), 1713-1716, Catedral, Granada.

\section{LOS PRIMEROS VIAJES A GRANADA (1713-1716)}

En 1713 Pedro Duque Cornejo rondaba los 35 años. Resulta difícil creer, como tradicionalmente se había apuntado, que las granadinas fueran sus primeras obras. Esta laguna se ha subsanado parcialmente con el descubrimiento de nuevas piezas de sus años de juventud sevillanos ${ }^{14}$. Lo más probable es que la producción del joven Cornejo se diluyera, hasta 1699, en el taller de su abuelo Pedro Roldán, donde se había formado junto a sus padres y tíos. Otro tanto se puede decir del taller que su padre abrió a la muerte de su suegro en el citado año. La obra conocida de José Felipe

14 Nos referimos a las aportaciones de CARO QUESADA, María Salud, "Jerónimo Balbás en Sevilla", en Atrio, nº 0, 1988, pp. 63-91; ARENILLAS, Juan Antonio, "Juan del Castillo, un escultor del siglo XVIII en Marchena", en Atrio, n 1, 1989, pp. 81-82; SALAZAR FERNÁNDEZ, Rosa María, "Un grabado de Santa María del Subsidio: primera obra firmada de Pedro Duque Cornejo", en Laboratorio de Arte , n 9, 1996, pp. 359-364; RODA PEÑA, José, "Tres esculturas de Pedro Duque Cornejo para el Oratorio de San Felipe Neri de Sevilla”, en Atrio, no 8-9, 1996, pp. 240-251; HERRERA GARCÍA, Francisco Javier, "Un nuevo grabado y últimas obras documentadas en Sevilla de Pedro Duque Cornejo”, en Laboratorio de Arte , n 12, 1999, p. 245. 
Duque Cornejo es escasa y discreta, ligada por lo común al retablo. Éste es el legado que le deja a su hijo y es el panorama que encuentra Jerónimo Balbás a su llegada a Sevilla: la de un escultor talentoso, con la fama y el magisterio de su abuelo a las espaldas, que trabaja la escultura para el retablo como su padre. El zamorano apostó decididamente por Pedro Duque Cornejo desde el principio, con quien contó para la mayoría de sus empresas (retablos de la capilla sacramental de San Isidoro, del Sagrario y de San Felipe Neri).

La incuria de los tiempos nos ha privado de algunas de estas obras de juventud, mientras que otras aún deben permanecer en el anonimato. El estudio de las pocas obras que se le han podido documentar en estos años revela la producción de un artista notable, que no obstante apenas sobresale del panorama roldanesco que impregna la escultura sevillana de su tiempo. Su obra todavía está lejos de alcanzar la intensidad y la fuerza de su producción madura, aunque será en estos momentos cuando se forje su aptitud para el diseño, haciendo grabados e iniciándose en el campo de la retablística ${ }^{15}$.

Sin embargo, es precisamente en la segunda década del Setecientos, coincidente con sus años de Granada, cuando la obra de Cornejo comienza a brillar con luz propia. De ahí que este periodo sea clave para entender la génesis de su extraordinaria personalidad artística. En el XVIII, con los templos prácticamente construidos, darían comienzo los grandes programas decorativos del barroco granadino, que suponen una segunda Edad de Oro tras la experiencia de Cano. Se trataba del momento en que grandes figuras como el anciano José de Mora, su hermano Diego y el polifacético José Risueño - aún deudores de la gran herencia del racionero- coinciden en la ciudad con destacados artistas de otros centros como Hurtado, Cornejo y Palomino, que suponen un contrapunto artístico y estético al panorama local.

A la luz de nuestras investigaciones, compartimos con Taylor la creencia de que hubo contactos previos entre Hurtado Izquierdo y Duque Cornejo en Sevilla. Lo que no creemos tan probable es que su llegada en 1713 estuviera directamente relacionada con los púlpitos o, al menos, no sólo con ellos. Precisamente desde finales de 1712 o principios del año siguiente, la Hermandad de la Esclavitud de las Angustias ya se encontraba remodelando la iglesia parroquial para dar cabida a las catorce esculturas monumentales de los Apóstoles, el Salvador y María (fig. 2), que a la postre realizaría Pedro Duque Cornejo. No parece verosímil, pues, que la Hermandad hubiera dado comienzo a la obra sin tener elegido aún al escultor de las tallas. Por eso, en algún momento entre 1712 y 1713, Duque Cornejo sería designado para esculpirlas, quizás por recomendación del propio Hurtado, que precisamente aparece por aquel tiempo como veedor de las obras del camarín de las Angustias.

El primer viaje documentado de Duque Cornejo a Granada se fecha en junio de 1713 y precisamente está relacionado con el Apostolado. En dicho mes entregó los

15 En 1711 concertó un retablo para la parroquia de San Lorenzo de Sevilla, si bien nunca llegó a ejecutarse. Vid. HERRERA GARCÍA, Francisco Javier, El Retablo Sevillano en la primera mitad del siglo XVIII: Evolución y difusión del retablo de estípites, Sevilla, Diputación Provincial, 2001, p. 383. 


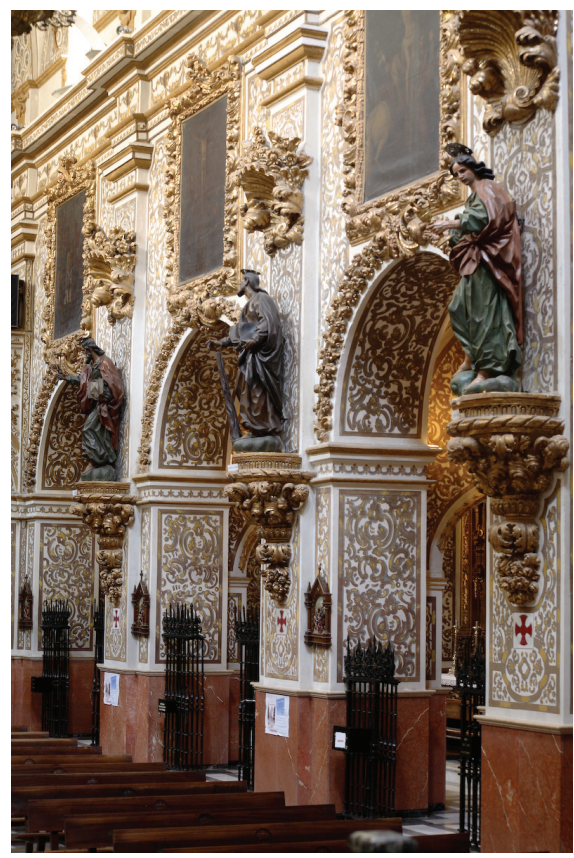

Fig. 2. Vista de la nave de la parroquia de Ntra. Sra. de las Angustias, Granada [Fotografía: Carlos Madero].

dos primeros Apóstoles, Santiago el Mayor y San Simón, siendo "agasajado" en el día de su santo (29 de junio) por la hermandad ${ }^{16}$.

El siguiente viaje nos traslada hasta 1714. Ya hemos visto como en abril del año anterior Hurtado Izquierdo había contratado los púlpitos de la catedral. Por la décima condición de la escritura, la parte escultórica debía ser "de razonable mano, de suerte que no [...] sea de las mas suprema, ni tanpoco aya de ser admisible la defectuosa, o infima" ". Aunque lamentablemente no queda rastro documental del autor de las esculturas, en las actas capitulares de 22 de septiembre de 1714 se dice que:

“el fabricante de las efixies de piedra [...] estava para hirse a Sevilla, para cuio efecto y por no hallarse oy en Granada el maestro maior a cuio cargo està la dicha obra, necesitava se le socorriese con zinco mil reales para quentta de lo que â dicho maestro le queda que tomar del precio en que se le conzerttó" ${ }^{18}$.

16 Para un análisis en profundidad, remitimos a nuestro trabajo "Un conjunto singular del barroco sevillano en Granada: el Apostolado de la basílica de las Angustias, obra de Pedro Duque Cornejo", en Cuadernos de Arte de la Universidad de Granada, $\mathrm{n}^{\circ} 41,2010$, pp. 171-190.

17 [A]rchivo [H]istórico del [A]rzobispado de [G]ranada, Armario 3, estante 5, n. ${ }^{\circ}$ 21, fols. 37-43. El contrato fue descubierto por Gila Medina. Cf. el corpus documental de GILA MEDINA, Lázaro (coord.), El libro de la Catedral de Granada, t. II, Granada, Cabildo Metropolitano de la S. I. Catedral, 2005, p. 1401.

18 [A]rchivo [C] atedral de [G]ranada, Libro $22^{\circ}$ de actas capitulares, fol. $263 \mathrm{v}^{\circ}$. 


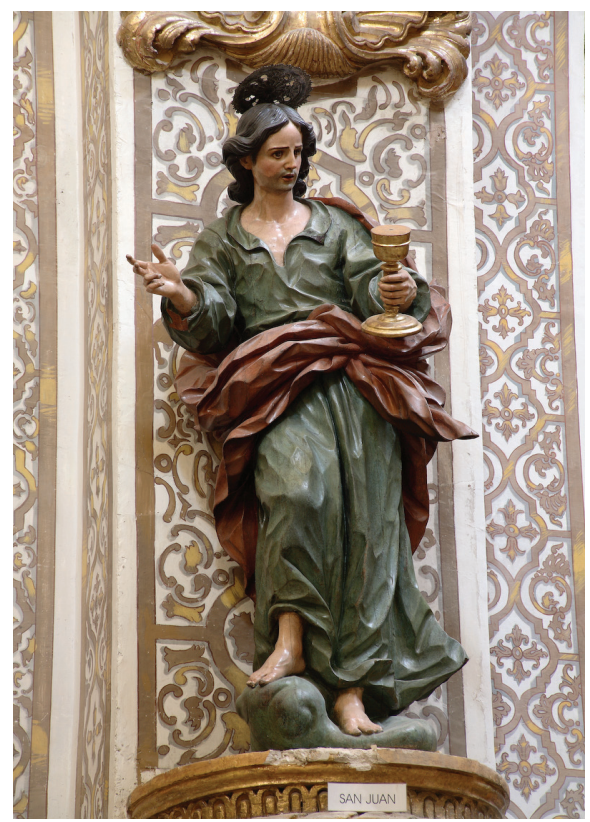

Fig. 3. Pedro Duque Cornejo, San Juan, 1715-1716, Parroquia de Ntra. Sra. de las Angustias, Granada [Fotografía: Carlos Madero].

Todo apunta a que este "fabricante" que subcontrató las esculturas y quería volver a Sevilla era Duque Cornejo, como pensó Taylor ${ }^{19}$. Durante el verano, él y su taller habrían terminado de esculpir los diez medallones de los Evangelistas, los Padres de la Iglesia, el Salvador y la Virgen, más seis ángeles y seis leones para la base de los púlpitos. Desde luego que la dureza del material -mármol blanco de Luque- condicionaría el acabado blando de las figuras, pese a todo relacionables con su estilo.

El tercer viaje de Pedro Cornejo a la capital granadina llegaría entre el verano de 1715 y junio de 1716. En dicho periodo tuvo que hacer una importante entrega de otras ocho esculturas para el Apostolado de las Angustias (fig. 3), que fueron trasladadas desde "las casas del artífice" y le fueron pagadas a él y al también "artífice" Diego Ruiz Palacios ${ }^{20}$. Este último no era otro que su cuñado, casado con Juana Cornejo y afincado en la calle del Candil de Granada desde al menos $1713^{21}$. Por lo tanto, es probable que las referidas casas hicieran referencia a esta vivienda y que el matrimonio estuviera integrado en el taller de Duque ${ }^{22}$.

19 TAYLOR, René (1978a), op. cit., p. 190.

20 GARCÍA LUQUE, Manuel (2010), op. cit.

21 [A]rchivo [P] arroquial de [S] an [P]edro y [S]an [P] ablo de [G]ranada, Libro $3^{\circ}$ de los padrones de la yglesia parroquial de San Pedro desde el año de 1710 hasta el de 1719 inclusive, s/f, Año de 1713, Calle del Candil, Casa 72. Junto al matrimonio viven María Ruiz Palacios y Diego del Mármol.

22 De hecho, es bastante probable que el matrimonio hubiera abierto taller en Granada hacia 1713 a propósito del encargo del Apostolado. Cabría pensar incluso que, al igual que ocurrió con el retablo de la 
Ciertamente tampoco podemos descartar que Duque Cornejo hubiera viajado de motu propio a la ciudad, sin la mediación de Hurtado, en busca de nuevos horizontes profesionales. Además de la constatada presencia de estos familiares directos, también es probable que contara con otros parientes lejanos, teniendo en cuenta que tres de sus abuelos (los dos paternos y su abuela materna) eran naturales de Granada.

\section{EL TALLER SEVILLANO (1713-1716)}

En paralelo a sus viajes, Duque Cornejo continuó al frente de su obrador sevillano. Recientemente había adquirido las casas de su abuelo Pedro Roldán en la calle Beatos, donde él se había criado y formado. La vivienda, que amenazaba ruina, le fue comprada a la viuda de su tío Marcelino Roldán en $1711^{23}$. Por entonces su taller, además de trabajar en los Apóstoles y en los púlpitos, estaría ocupado en la escultura del retablo mayor de la iglesia de San Antonio Abad de Trigueros (Huelva). El retablo, desaparecido, había sido contratado en septiembre de 1713 por el ensamblador Miguel Franco, actuando Duque Cornejo como fiador ${ }^{24}$.

Un año más tarde, a la vuelta de entregar las piezas de los púlpitos en Granada, Duque Cornejo cancela el arrendamiento de una casa con el marqués de Vallehermoso, en diciembre de $1714^{25}$. Por aquel tiempo, su mujer estaba esperando su tercer hijo, Manuel, que fue bautizado el 22 de junio de 1715 en la parroquia de Santa Marina ${ }^{26}$. Además de este acontecimiento, otro lo sitúa en agosto en Sevilla. Al concurso para realizar la sillería de coro de la iglesia de San Juan Bautista de Marchena se presentó Jerónimo Balbás, imponiendo como condición que la parte escultórica correría a cargo de "don Pedro Cornejo, por ser el mas ynteligentte que ai en esta ciudad, porque siempre en esta expecie de obras es principal objeto la scultura"27. Probablemente este dato dio lugar a las atribuciones decimonónicas que señalaban a Cornejo como autor de la sillería. Sin embargo, sabemos que, tras numerosas pujas y contrapujas, finalmente fue tallada por otros maestros, si bien siguiendo la traza balbasiana ${ }^{28}$.

Aunque el encargo de Marchena no salió adelante, Cornejo continuaba trabajando en el retablo de Trigueros, que enseguida comenzaría a darle problemas. En agosto

Antigua, Diego Ruiz Palacios saliera como fiador; cuestión que permanecerá sin resolver hasta que no aparezca el contrato, que bien pudo perderse en el incendio que el Archivo de Protocolos sufrió en el siglo XIX.

23 HERRERA GARCIA, Francisco Javier, Noticias de arquitectura (1700-1720) [col. Fuentes para la Historia del Arte Andaluz, vol. II], Sevilla, Guadalquivir, 1990, p. 132.

24 La historia detallada en CARRASCO TERRIZA, Manuel, "El retablo mayor de Trigueros, obra de Miguel Franco, Duque Cornejo y Pedro Roldán (I)", en Boletín Oficial del Obispado de Huelva, $\mathrm{n}^{\circ}$ 254, marzo-abril de 1985, pp. 117-124 y "El retablo mayor de Trigueros, obra de Miguel Franco, Duque Cornejo y Pedro Roldán (II)", en Boletín Oficial del Obispado de Huelva, n 255, mayo-junio de 1985, pp. 179-185.

25 CARO QUESADA, María Salud, Noticias de escultura (1700-1720) [col. Fuentes para la Historia del Arte andaluz, vol. III], Sevilla, Guadalquivir, 1992, p. 86.

26 SANCHO CORBACHO, Heliodoro, Arquitectura sevillana del siglo XVIII [col. Documentos para la Historia del Arte en Andalucía, vol. VII], Sevilla, Laboratorio de Arte, 1934, p. 8.

27 CARO QUESADA, María Salud (1992), op. cit., p. 83.

28 HERRERA GARCÍA, Francisco Javier (2001), op. cit., pp. 351-353. Juan de Valencia y Miguel de Perea se hicieron con el encargo. 
de 1715 , los escasos 18.000 reales estipulados en el contrato se habían acabado y el retablo estaba sin concluir. En consecuencia, Miguel Franco solicitó más dinero a la parroquia triguerense, la cual obviamente se negó en rotundo. El desentendimiento entre ambas partes los llevó ante la Audiencia de Sevilla, que terminó por dar la razón a la parroquia y obligar a los artistas a terminar el retablo; y dado que Miguel Franco se declaró insolvente, la obligación pasó a su fiador, Pedro Duque Cornejo ${ }^{29}$. Éste u otros problemas lo llevaron el 2 de diciembre a otorgar poderes a los procuradores para que lo defendieran en sus pleitos ${ }^{30}$.

A pesar de estos problemas, y contemporáneamente a su tercer viaje a Granada, el nieto de Roldán continuó recibiendo encargos en Sevilla. En la Navidad de 1715 recibió un regalo de Pascua de la Hermandad Sacramental de San Bernardo, porque les estaba haciendo un pequeño sagrario con cuatro esculturas, que acabó en marzo de 1716. Poco después tallaría para la citada Hermandad dos pequeños relieves, pagados en agosto ${ }^{31}$.

Las cosas, sin embargo, se truncaron en aquel verano de 1716. En septiembre, Duque Cornejo envió una carta al vicario de Trigueros, cuya lectura nos ofrece una imagen verdaderamente novelesca de sus desventuras, hasta ahora poco conocidas. En la misiva se excusa por la demora en los trabajos del retablo puesto que en aquel verano le había sido reclamado un préstamo por vía ejecutiva, hasta tal punto que se había ordenado su encarcelamiento. Estando buscado por la justicia, el escultor se vio obligado a refugiarse en el noviciado jesuítico de San Luis de las Franceses, inmediato a su casa de la calle Beatos, amparándose en el derecho de asilo en suelo sacro ${ }^{32}$. $\mathrm{Su}$ declaración se puede contrastar con los documentos notariales, que certifican que el 9 de agosto de 1716 otorgó nuevos poderes a los procuradores ${ }^{33}$.

A los pocos días de escribir esta carta desde San Luis, Duque Cornejo tomaría rumbo a Granada. Dejaba pendiente el trabajo para Trigueros, que pasaría de nuevo a Miguel Franco (apresado en noviembre en Bonares) y que finalmente sería acabado gracias a la intervención de su tío, Pedro Roldán $E l \mathrm{MozO}^{34}$.

\section{EL TRASLADO DEL TALLER A GRANADA (1716-1719)}

Al menos para el 2 de octubre de 1716, Duque Cornejo ya se encontraba instalado en Granada, pues recibió dinero y madera a cuenta del Apostolado, para ponerse a trabajar cuanto antes ${ }^{35}$. Semanas más tarde, contrataría el nuevo retablo para la capi-

9 CARRASCO TERRIZA, Manuel J. (1985a), op. cit., p. 120 y n. 20.

30 CARO QUESADA, María Salud (1992), op. cit., p. 86.

31 RODA PEÑA, José, "Pedro Duque Cornejo en la capilla sacramental de la parroquia de San Bernardo de Sevilla", en Laboratorio de Arte, no 11, 1998, p. 572.

32 CARRASCO TERRIZA, Manuel J. (1985a), op. cit., p. 121. Este hecho ha sido subrayado recientemente por RAVÉ PRIETO, Juan Luis, San Luis de los Franceses [col. Arte Hispalense , n. ${ }^{\circ}$ 89], Sevilla, Diputación, 2010.

33 CARO QUESADA, María Salud (1992), op. cit., p. 87.

34 CARRASCO TERRIZA, Manuel (1985a), op. cit., p. 122.

35 GARCÍA LUQUE, Manuel (2010), op. cit. 
1la de Nuestra Señora de la Antigua en la catedral (fig. 4), por encargo del arzobispo Martín de Ascargorta. El escultor, "estante y residente" en Granada, se comprometía a ejecutarlo por la elevada suma de 4.000 ducados $^{36}$.

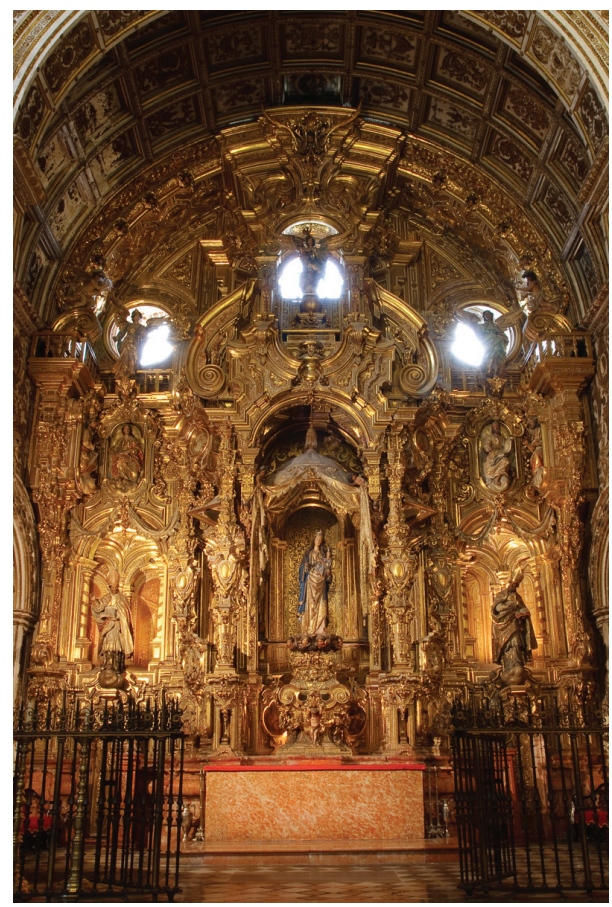

Fig. 4. Pedro Duque Cornejo, Retablo de Nuestra Señora de la Antigua, 1716-1718, Catedral, Granada.

No es casual que su cuñado, Diego Ruiz, saliera como fiador en este contrato, pues fue precisamente en su casa de la calle del Candil donde en principio se instalaron Cornejo junto a su mujer Isabel de Arteaga, Teresa Roldán Villavicencio y Pedro Castillejos -tíos maternos del escultor-y probablemente sus tres hijos pequeños: María, Enrique y Manuel, de cinco, tres y un años. El padrón parroquial de abril de 1717 registra la presencia de todos ellos en la misma casa ${ }^{37}$, junto a María Palacios, Ana María de Castillejo, Vicente Ruiz y José38. También en el padrón de 1718, todos,

36 GALLEGO Y BURÍN, Antonio (1956), op. cit., pp. 154-158.

37 A.P.S.P.S.P.G., Libro $3^{\circ}$ de los padrones de la yglesia parroquial de San Pedro desde el año de 1710 hasta el de 1719 inclusive, s/f, Año de 1717, Calle del Candil, Casa 71.

38 Doña María [Ruiz] Palacios aparece desde el principio viviendo junto con Diego Ruiz Palacios y Juana Duque Cornejo. Más que de una hija, podría tratarse de una hermana de Diego. La ausencia del tratamiento "don" en los tres últimos inquilinos puede aludir a su minoría de edad: Ana María Castillejos puede ser hija de Pedro Castillejos; de Vicente Ruiz sólo sabemos que también aparece en el padrón de 1715; y José debe ser el hijo de Diego Ruiz Palacios, que aparece en padrones sucesivos, y que bien pudiera identificarse con el 
a excepción de Vicente Ruiz, seguían viviendo en la misma casa, junto a tres nuevos inquilinos: Francisco Miguel Valladolid, María Dorador y José Méndez, mayores de edad y probablemente integrantes del taller de Duque Cornejo ${ }^{39}$.

Desde luego, esta elevada presencia de familiares y posibles oficiales de su taller en la ciudad no es baladí. Es cierto que Cornejo tenía algunos encargos pendientes de conclusión en Granada y que probablemente antes de su llegada ya estuviera negociando con el arzobispo el nuevo retablo de la Antigua. Sin embargo, nada de esto justifica tan aparatoso traslado de personal, pues el altar perfectamente podía haber sido tallado en su taller sevillano, para posteriormente ser montado en Granada.

A nuestro juicio, varias pudieron ser las motivaciones de su traslado, aunque fundamentalmente dos: que fuera una exigencia del prelado, celoso del cumplimiento de la escritura del retablo, para que así los comisarios pudieran visitar su taller en la ciudad; y, sobre todo, que se tratara de una decisión personal de Pedro quien, perseguido por la justicia en Sevilla, buscara refugio en Granada, a la espera de vientos favorables. Sea como fuere, lo cierto es que esta nueva etapa en el horizonte vital de Duque Cornejo arranca en el otoño de 1716 y se prolonga hasta algún momento de 1719. El sevillano se asentó en un lugar estratégico de la Granada barroca como la ca1le del Candil, situada a los pies de la Alhambra y conectando la carrera del Darro con la calle de San Juan de los Reyes, verdaderas arterias urbanas en torno a las cuales se había instalado la nobleza castellana tras la conquista. En estos años su mujer daría a luz a dos de sus hijos, que fueron bautizados en la vecina parroquia de San Pedro y San Pablo: Pedro, el 2 de mayo de 1717, apadrinado por la hermana y el cuñado de Cornejo; e Isidro, el 5 de enero de 1719, apadrinado por sus tíos Teresa Roldán Villavicencio y Pedro Castillejos ${ }^{40}$.

Éstos serían años de febril actividad artística. A lo largo de 1717, su taller acabaría el Apostolado. La Hermandad de la Esclavitud, que se esmeró en complacer al artista con abundantes regalos, recibió los seis últimos apóstoles el 10 de enero de $1718^{41}$. También el retablo de la Virgen de la Antigua, que en principio debía haberse acabado para agosto, tuvo que realizarse durante 1717 y estar prácticamente listo a comienzos del año siguiente, pues en febrero se mandó quitar el anterior retablo ${ }^{42}$.

Aún después de acabar ambas empresas a comienzos de 1718, otros encargos retuvieron al sevillano en la ciudad. Ya hemos visto como en abril, cuando cobra unas

escultor José Palacios que registra el catastro de la Ensenada en Granada hacia 1752 (contaba entonces con 40 años). Vid. LÓPEZ MUÑOZ, Juan Jesús y LÓPEZ MUÑOZ, Miguel Luis, "Artes y oficios artísticos en Granada a mediados del siglo XVIII", en Espacio, Tiempo y Forma, Serie VII, H. ${ }^{a}$ del Arte, t. IX, 1996, p. 177.

39 A.P.S.P.S.P.G., Libro $3^{\circ}$ de los padrones..., s/f, Año de 1718, Calle del Candil, Casa 82. En esta ocasión, el padrón fue algo más detallado y señaló con dos marcas a los adultos (") y con una (') a los menores. María Dorador aparecerá avecindada en la misma calle en años sucesivos, como 1722.

40 GILA MEDINA, Lázaro, "El Apostolado, el Salvador y la Virgen de la parroquia-basílica de Nuestra Señora de las Angustias de Granada, obra de Duque Cornejo, a la luz de la documentación”, en FERNÁNDEZ GRACIA, Ricardo (coord.), Pulchrum: Scripta Varia in Honorem María Concepción García Gaínza, Pamplona, Gobierno Foral de Navarra, 2011, pp. 357-365.

41 GARCÍA LUQUE, Manuel (2010), op. cit.

42 LÓPEZ-GUADALUPE MUÑOZ, Juan Jesús, "La catedral vestida: la arquitectura de los retablos”, en GILA MEDINA, Lázaro (2005), op. cit., t. I, p. 511. 


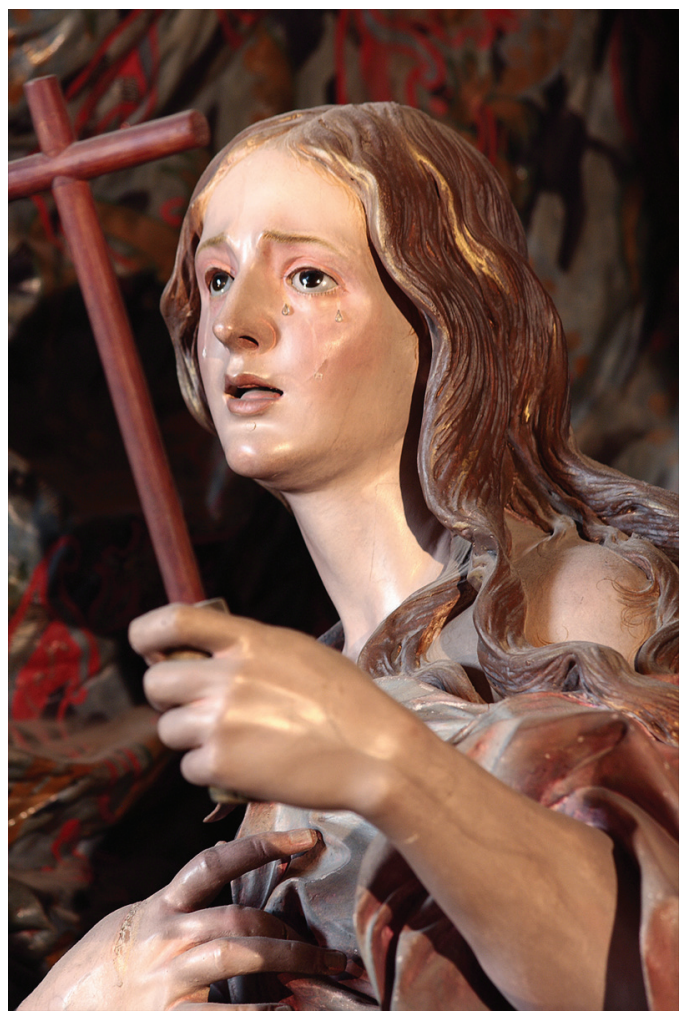

Fig. 5. Pedro Duque Cornejo, Magdalena penitente, 1716-1719, Cartuja de Ntra. Sra. de la Asunción, Granada.

manos nuevas para la Virgen de las Angustias ${ }^{43}$, aparece todavía viviendo en casa de Diego Ruiz. Sin embargo, tiempo después, acabado el retablo que ambos habían contratado, Duque Cornejo se mudaría. En el padrón de abril de 1719, tanto él como Isabel de Arteaga, José de Arteaga ${ }^{44}$, Enrique y María Duque Cornejo, María Dorador, Pedro Castillejos, Teresa Roldán y Ana María Castillejos continúan viviendo en la calle del Candil, aunque en una casa distinta a la de su hermana y cuñado ${ }^{45}$.

Esta prolongación de la estancia entre 1718-1719 evidencia que su taller estaba enfrascado en otros trabajos: la culminación de otro conjunto escultórico de primer orden, como el del Sancta Sanctorum de la cartuja (fig. 5); o quizás ejecutando otros

43 [A]rchivo de la [R]eal [H]ermandad de Nuestra Señora de las [A]ngustias de [G]ranada, Libro de cargo y descargo de los Mayordomos de la Hermandad de Nra. Sra. De las Angustias de esta Ciudad. Año de 1698-1728, Cuentas de abril de 1718, s/f.

44 Podría tratarse del hermano pequeño de Isabel de Arteaga, cuñado de Pedro Duque, nacido en 1711 y apadrinado por él mismo y su hermana Juana. Vid. HOWARD, Ryan Abney (1975), op. cit., p. 39.

45 A.P.S.P.S.P.G., Libro $3^{\circ}$ de los padrones..., s/f, Año de 1719, Calle del Candil, Casas 70 y 80 , respectivamente. 
retablos desaparecidos, como el mayor de los agustinos recoletos de Loreto ${ }^{46}$ o el retablito para el hospital de San Juan de Dios ${ }^{47}$.

A finales de aquel año, o principios del siguiente, debió abandonar la ciudad, pues en febrero de 1720 se le documenta nuevamente en Sevilla ${ }^{48}$. Desde luego, con el problema de Trigueros solucionado y sus dos protectores granadinos fuera de juego (el arzobispo Ascargorta fallecido y Hurtado Izquierdo residiendo en Priego), se trataba del momento idóneo para retornar a su ciudad natal, donde vendría a llenar el vacío dejado por Jerónimo Balbás, emigrado a la Nueva España. No obstante, su hermana y su cuñado permanecerían en Granada ${ }^{49}$.

En síntesis, podemos concluir que gracias a estas noticias documentales los años granadinos de Duque Cornejo se perfilan cada vez más nítidos; y que esta experiencia, aunque relativamente breve, fue altamente significativa para la maduración de su estilo. Ciertamente, su labor como retablista no se entendería si a su formación balbasiana no añadimos el bagaje aprendido con Hurtado Izquierdo; del mismo modo que el contacto con la escultura granadina, tremendamente sugestionada por la plástica de José de Mora, le permitió sumar nuevas cotas de intensidad expresiva a su barroquismo roldanesco y tomar contacto con las figuras ahusadas de origen canesco.

\footnotetext{
46 CHICA BENAVIDES, Fray Juan de la, Gazetilla curiosa o semanero granadino, noticioso y útil para el bien común, Granada, Imp. de la Santísima Trinidad, 1764-1765, Papel XXI, Pliego I.

47 PARRA Y COTE, Alonso (O. H.), Desempeño el mas honroso de la obligacion mas fina, y relacion historico-panegyrica de las fiestas de dedicacion del magnifico templo de la Purisima Concepcion de Nuestra Señora, del Sagrado Orden de Hospitalidad de N.P. San Juan de Dios de la nobilissima, e ilustre, siempre fiel ciudad de Granada [...], Madrid, Imp. de Francisco Xavier García, 1759, p. 188.

48 CARO QUESADA, María Salud (1992), op. cit., p. 87. Duque Cornejo manda cobrar las rentas de una casa en la collación de San Marcos.

49 Hasta 1721 continuaron en la misma casa de la calle Candil. A.P.S.P.S.P.G., Libro $4^{\circ}$ de los padrones de la yglesia parroquial de San Pedro desde el año de 1720 hasta el de 1729 inclusive, s/f, Años 1720 y 1721.
} 